\title{
Article \\ Fabrication of All-GaN Integrated MIS-HEMTs with High Threshold Voltage Stability Using Supercritical Technology
}

\author{
Meihua Liu (D, Yang Yang, Changkuan Chang, Lei Li and Yufeng Jin * \\ School of Electronic and Computer Engineering, Peking University Shenzhen Graduate School, University Town, \\ Xili, Nanshan, Shenzhen 518055, China; liumh@pku.edu.cn (M.L.); yang1994@pku.edu.cn (Y.Y.); \\ kcchang@pkusz.edu.cn (C.C.); lilei@pkusz.edu.cn (L.L.) \\ * Correspondence: yfjin@pku.edu.cn
}

Citation: Liu, M.; Yang, Y.; Chang, C.; Li, L.; Jin, Y. Fabrication of All-GaN Integrated MIS-HEMTs with High Threshold Voltage Stability Using Supercritical Technology. Micromachines 2021, 12, 572. https:// doi.org/10.3390/mi12050572

Academic Editor: Giovanni Verzellesi

Received: 19 April 2021

Accepted: 15 May 2021

Published: 18 May 2021

Publisher's Note: MDPI stays neutral with regard to jurisdictional claims in published maps and institutional affiliations.

Copyright: (c) 2021 by the authors. Licensee MDPI, Basel, Switzerland. This article is an open access article distributed under the terms and conditions of the Creative Commons Attribution (CC BY) license (https:// creativecommons.org/licenses/by/ $4.0 /)$.

\begin{abstract}
In this paper, a novel method to achieve all-GaN integrated MIS-HEMTs in a Si-CMOS platform by self-terminated and self-alignment process is reported. Furthermore, a process of repairing interface defects by supercritical technology is proposed to suppress the threshold voltage shift of all GaN integrated MIS-HEMTs. The threshold voltage characteristics of all-GaN integrated MIS-HEMTs are simulated and analyzed. We found that supercritical $\mathrm{NH}_{3}$ fluid has the characteristics of both liquid $\mathrm{NH}_{3}$ and gaseous $\mathrm{NH}_{3}$ simultaneously, i.e., high penetration and high solubility, which penetrate the packaging of MIS-HEMTs. In addition, $\mathrm{NH}_{2}^{-}$produced via the auto coupling ionization of $\mathrm{NH}_{3}$ has strong nucleophilic ability, and is able to fill nitrogen vacancies near the GaN surface created by high temperature process. The fabricated device delivers a threshold voltage of $2.67 \mathrm{~V}$. After supercritical fluid treatment, the threshold voltage shift is reduced from $0.67 \mathrm{~V}$ to $0.13 \mathrm{~V}$. Our demonstration of the supercritical technology to repair defects of wide-bandgap family of semiconductors may bring about great changes in the field of device fabrication.
\end{abstract}

Keywords: GaN; MIS-HEMTs; fabrication; threshold voltage stability; supercritical technology

\section{Introduction}

GaN-based high electron mobility transistors (HEMTs) are good candidates for high frequency and high efficiency power switching applications owing to their attractive superiorities of high breakdown electric field and high saturation electron velocity [1]. Normally-off property is strongly required for $\mathrm{GaN}$ devices used in the power electronics systems. To date, there are totally four possible ways to realize enhance-mode (E-mode) GaN devices, which are (a) cascode configuration [2], (b) P-GaN gate GaN HEMT, (c) recessed gate GaN MIS-HEMT or MIS-FET and (d) fluoride implanted gate GaN (MIS-) HEMT. Among them, cascode structure is compatible with Si CMOS platform reducing the production cost and complexity. Furthermore, the Miller capacitance is eliminated because of blocking the reverse recovery diode by GaN devices, thus improving the switching speed and reducing the switching loss [3].

However, a few issues have been reported that may negate the speed advantage in the GaN plus Si hybrid cascode devices, such as increased parasitic inductance [4] and mismatch in intrinsic capacitances between the $\mathrm{Si}$ and GaN devices [5]. All-GaN integrated cascode device by replacing the Si MOSFET with a low voltage GaN E-mode device achieved using fluoride ion implantation has proven to be able to address the issues mentioned above and improve the switching speed [3]. However, fluoride ion implantation tends to result in $\mathrm{V}_{t h}$ instability and drain current degradation in HEMTs [6]. In addition, fluoride ion implantation requires high energy, and it is difficult to realize general silicon process lines.

Furthermore, metal-insulator-semiconductor (MIS) gate structure is typically adopted to maintain a relatively large gate swing a low gate leakage current. However, there are several raliability issues realted to GaN MIS-HEMTs. When a positive gate bias is applied, 
defects located in the gate stack act as charge trapping sites. This induces a shift of the device transfer characteristics toward more positive values $[7,8]$.

Generally, the trapping effect in an MIS gate stack could be related to the traps at/near the interface, named interface states/border traps, or in the bulk of the insulator [9]. There have been several techniques used to suppress threshold voltage shift to date, including pre-fluorination argon treatment [10], sputter-deposited $\mathrm{Al}_{2} \mathrm{O}_{3}$ [11], in-situ pre-deposition plasma nitridation [12], metal-organic chemical vapor deposition-grown in situ SiN [13,14], hybrid ferroelectric charge trap gate stack [15], etc., to reduce the trapping effect at/near the insulator/semiconductor interface. Due to the low deposition temperature, there also exists large density of traps in the bulk of the gate insulators deposited by PECVD or ALD. Recently, high temperature deposited gate insulator, such as low-pressure chemical vapor deposition (LPCVD) grown $\mathrm{SiN}_{x}$ has been proven to be a robust gate dielectric for both normally-on GaN MIS-HEMTs and normally-off gate recessed hybrid MIS-HEMTs with low bulk trap density. However, the interface quality between LPCVD SiN $_{x}$ and (Al)GaN is degraded due to the high growth temperature and $\mathrm{H}$ erosion. Despite that low temperature deposited insertion layer or $\mathrm{N}$ surface plasma treatment have been adopted to improve the interface quality, the drift of $\mathrm{V}_{t h}$ still exists in those devices. Supercritical fluid technology can effectively bring elements into materials through supercritical $\mathrm{CO}_{2}$ fluid to reduce trap density because of its penetration and damage-free diffusion ability in the devices [16] Supercritical technology has been applied in the field of memory [17] and LED [18], but there is no research on the effectiveness of $\mathrm{GaN}$ power devices.

In this work, a new way is presented to achieve all-GaN integrated MIS-HEMTs in a Si CMOS platform by replacing the Si MOSFET with a low voltage GaN recessed gate MIS-HEMT. In the process, self-terminated gate open method and quasi-self-alignment technology are adopted allowing the recessed gate was defined and fabricated at the beginning of the process. In addition, we propose the application of supercritical nitridation treatment (SNT) to passivate the defects and mitigate the shift of $\mathrm{V}_{t h}$ in the all-GaN MISHEMTs. After SNT, the interface trap density in LPCVD Si ${ }_{3} \mathrm{~N}_{4} / \mathrm{AlGaN}$ layer interface is effectively reduced and near $0.13 \mathrm{~V}$ shift of $\mathrm{V}_{t h}$ in the transfer curve of a GaN power device is observed with a bidirectional gate bias sweep up to $15 \mathrm{~V}$.

\section{Device Fabrications}

The AlGaN/GaN heterostructure was grown by the metal organic chemical vapor deposition(MOCVD) on a $\mathrm{Si}(111)$ substrate, which consists of a 4- $\mu \mathrm{m}$ C-doped GaN buffer layer, a 300-nm unintentionally doped GaN channel layer, a 1-nm AlN insertion layer, a $25-\mathrm{nm} \mathrm{Al}_{0.25} \mathrm{Ga}_{0.75} \mathrm{~N}$ barrier layer and a 3-nm GaN cap layer for improving surface morphology. On wafer Hall measurement yields a sheet resistance of $363 \Omega$ /square, a 2DEG density of $1.1 \times 10^{13} \mathrm{~cm}^{-2}$, and an electron mobility of $1547 \mathrm{~cm}^{2} / \mathrm{V} \cdot \mathrm{s}$. The reported devices were fabricated in Founder Microelectronics International Corporation, Ltd, a 6-inch Si CMOS platform.

The main process flow is:

(1) Defining (Figure 1(2)) of the mesa isolation by $\mathrm{Cl}_{2} / \mathrm{BCl}_{3}$ based plasma etching.

(2) Patterning (Figure 1(3)) of the recessed gate by etching the AlGaN layer completely.

(3) Deposition of a 35-nm $\mathrm{Si}_{3} \mathrm{~N}_{4}$ layer using low pressure chemical vapor deposition (LPCVD) (Figure 1(4)). The $\mathrm{Si}_{3} \mathrm{~N}_{4}$ layer acts as a surface passivation layer and a gate insulator. The LPCVD $\mathrm{Si}_{3} \mathrm{~N}_{4}$ exhibits good insulating property and passivation effects.

(4) Deposition of a 500-nm oxide layer over the $\mathrm{Si}_{3} \mathrm{~N}_{4}$ layer by plasma enhanced chemical vapor deposition (PECVD) (Figure 1(5)). The oxide layer acts as the plasma etching sacrificial layer in the follow process patterning source and drain contacts and gate strips, and the gate field plate dielectrics.

(5) Opening (Figure 1(6)) of the source and drain contact windows by etching the oxide layer,the $\mathrm{Si}_{3} \mathrm{~N}_{4}$ layer and partial AlGaN layer .

(6) Deposition of $\mathrm{Ti} / \mathrm{Al} / \mathrm{Ti} / \mathrm{TiN}$ multi metal layers by physical vapor deposition (PVD) as ohmic metal and Patterning (Figure 1(7)) of the source and drain electrode. 
(7) Metallization by rapid thermal annealing at $850^{\circ} \mathrm{C}$ for $30 \mathrm{~s}$ in ambient $\mathrm{N}_{2}$ (Figure $1(8)$ ).

(8) Patterning (Figure 1(9)) of the D-mode gate. In this step, the low power $\mathrm{SF}_{6}$-based inductively coupled plasma (ICP) etching and the buffered HF (BHF) wet etching were adopted sequentially to define the gate stem, realizing a self-terminated dielectric etching (PECVD SiO 2 /LPCVD $\mathrm{Si}_{3} \mathrm{~N}_{4}$ etching selectivity is 200:1) on the surface of the LPCVD $\mathrm{Si}_{3} \mathrm{~N}_{4}$ gate dielectric layer. The self-terminated nature guaranteed good performance uniformity along the whole wafer. Meanwhile, quasi-self-alignment is realized, the E-mode GaN HEMT recessed gate can be fabricated at the same time.

(9) Deposition of TiN/Ti/Al multi metal layers by PVD as gate metal and patterning (Figure 1(10)) of the gate electrode.

(10) After the PAD metal and Final passivation (Figure 1(11),(12)), the devices were annealed at $450{ }^{\circ} \mathrm{C}$ for $30 \mathrm{~min}$ in ambient $\mathrm{H}_{2}$.
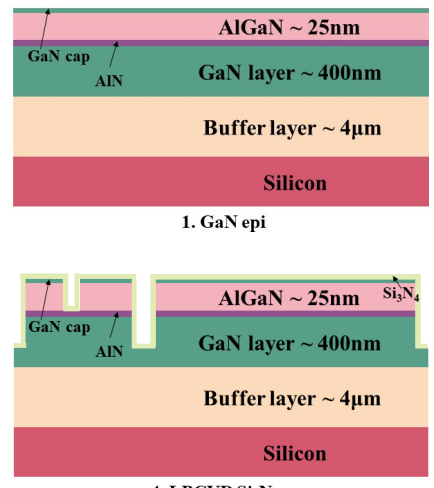

4. $\mathrm{LPCVDSi}_{3} \mathrm{~N}_{4}$

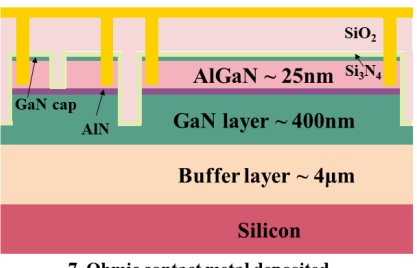

7. Ohmic contact metal deposited

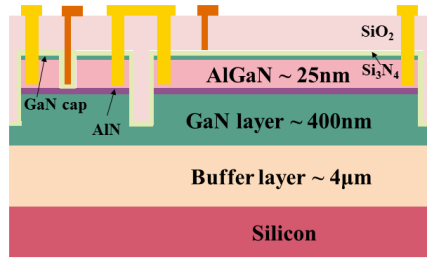

10. Gate metal deposited and patterned

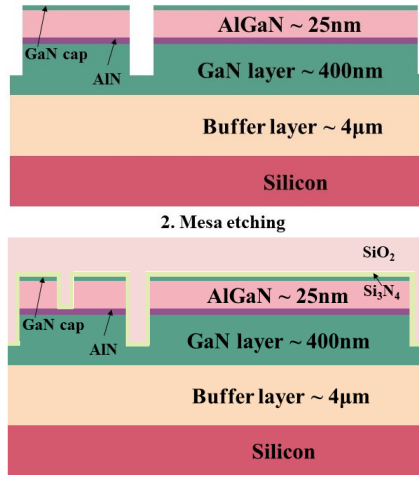

5. $\mathrm{SiO}_{2}$ passivation layer deposited by $\mathrm{PECVD}$

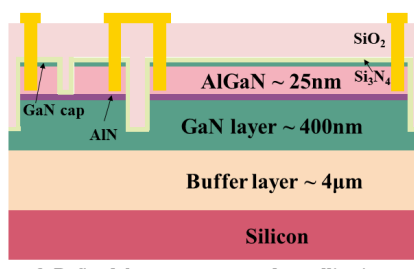

8. Defined the contact area and metallization

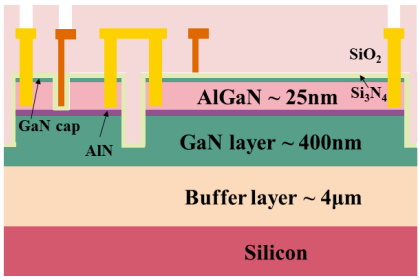

11. Defined the pad area

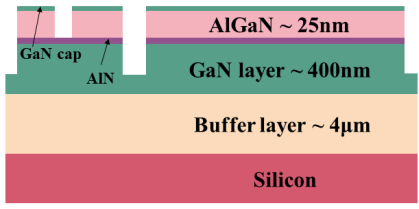

3. E-mode HEMTs recessed gate etching

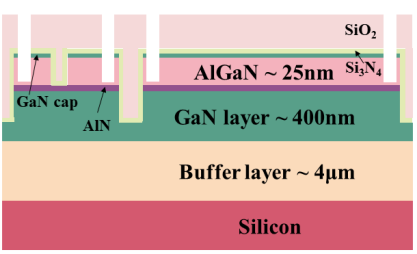

6. Defined Ohmic contact are

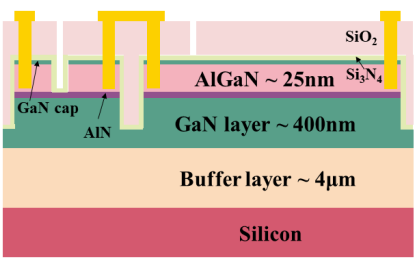

9. Defined the gate area

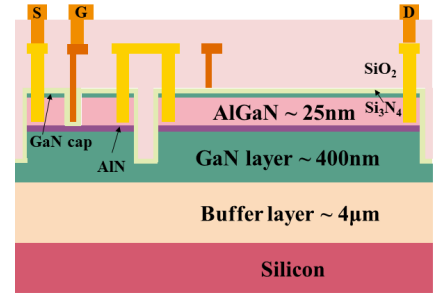

12. Pad metal deposited and patterned

Figure 1. (1-12) Main process steps of the all GaN integrated MIS-HEMT in CMOS fab.

Figure 1 shows schematics flow of the all-GaN integrated devices The characterization was performed on the devices with a dimension of $\mathrm{L}_{G} / \mathrm{L}_{G S} / \mathrm{L}_{G D} / \mathrm{W}=2 / 4.5 / 3 / 24 \mu \mathrm{m}$ for recessed gate MIS-FET and a dimension of $\mathrm{L}_{G} / \mathrm{L}_{G S} / \mathrm{L}_{G D} / \mathrm{W}=1 / 4.5 / 8 / 24 \mu \mathrm{m}$ for D-mode MIS-HEMT. Figure 2 shows the schematic view and cross-section TEM image of the fabricated all-GaN integrated MIS-HEMT. 


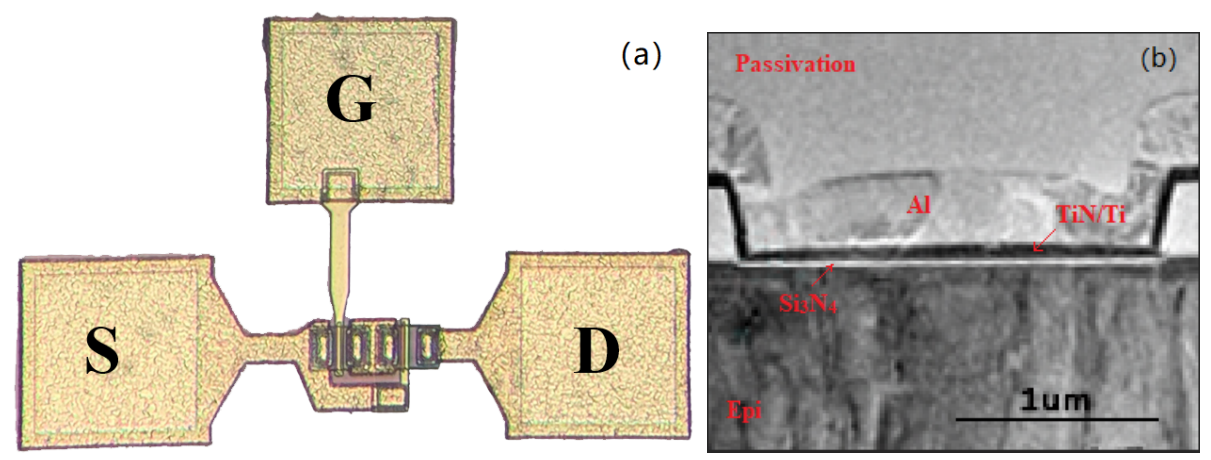

Figure 2. (a) Schematic view and (b) Cross-section TEM image of the fabricated all-GaN integrated MIS-HEMT.

\section{Results and Discussion}

All our electrical transport measurements were carried out in an Agilent B1500 semiconductor parameter analyzer and an automated Keithley SCS 4200 system.

\subsection{Transport Measurements}

Figure 3 shows the DC transfer characteristics and output characteristics of the fabricated all-GaN MIS-HEMTs. The $\mathrm{V}_{\text {th }}$ of the fresh device is about $2.67 \mathrm{~V}$ and the output saturation current is $305 \mathrm{~mA} / \mathrm{mm}$ at a gate bias of $12 \mathrm{~V}$. The $\mathrm{I}_{D S}-\mathrm{V}_{G S}$ transfer characteristics of the all-GaN MIS-HEMTs with and without SNT are shown in Figure 4. All the curves are swept in bidirectional mode at $\mathrm{V}_{D S}=1 \mathrm{~V}$. For the all-GaN MIS-HEMTs without SNT, significant hysteresis was observed during the sweep, suggesting severe trap-induced $\mathrm{V}_{\text {th }}$ shift.
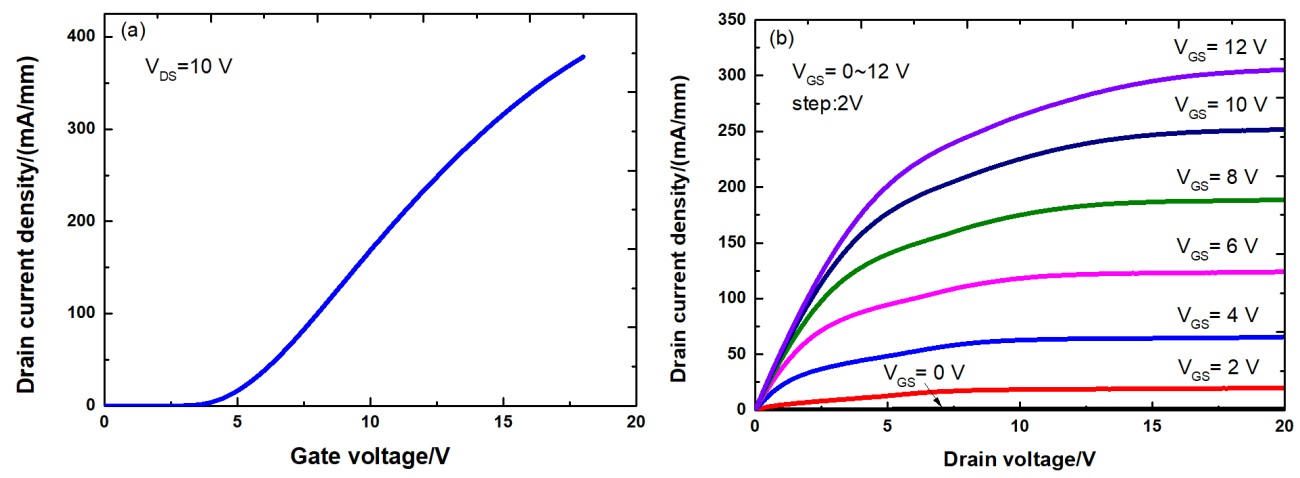

Figure 3. (a) DC transfer characteristics and (b) output characteristics of the fabricated all-GaN integrated MIS-HEMTs.
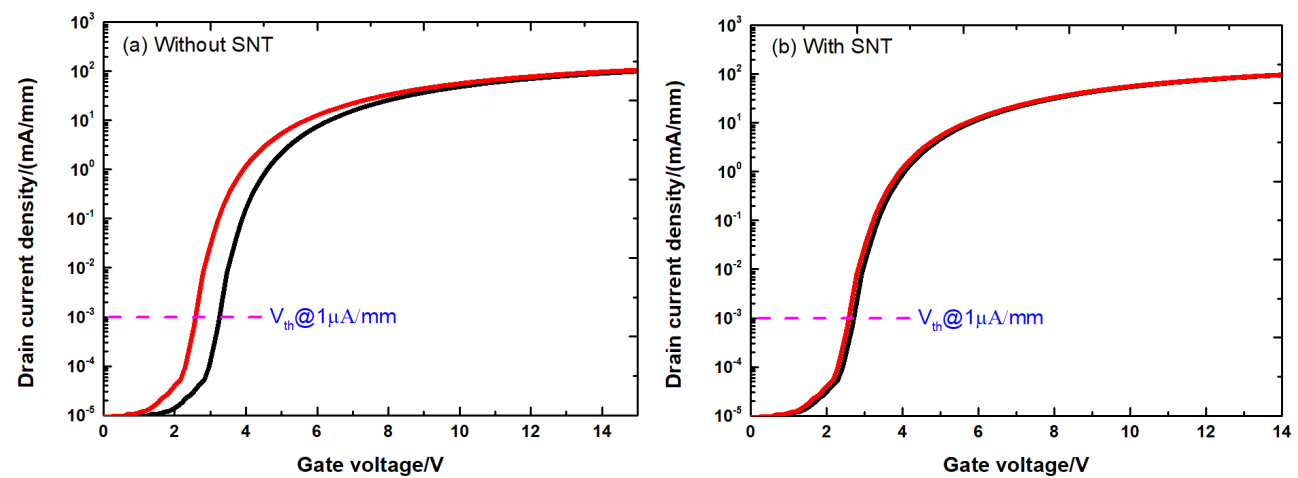

Figure 4. Transfer curves of the all-GaN integrated MIS-HEMTs in didiretional $\mathrm{V}_{G S_{s} \text { weep }}$ from $0 \mathrm{~V}$ to $15 \mathrm{~V}$ and then back to $0 \mathrm{~V}(\mathbf{a})$ without SNT and (b) with SNT. 


\subsection{Threshold Voltage Stability}

The temperature dependent $\mathrm{V}_{t h}$ hysteresis is evaluated by submitting the all-GaN integrated MIS-HEMTs to thermal simulation from $300 \mathrm{~K}$ to $370 \mathrm{~K}$ with a $10 \mathrm{~K}$ step at $\mathrm{V}_{D S}=1 \mathrm{~V}$. Figure 5 shows the transfer characteristics at various temperatures. When the temperature rises from $300 \mathrm{~K}$ to $370 \mathrm{~K}$, the threshold voltage shifts about $1.4 \mathrm{~V}$ without SNT. Meanwhile, when the temperature rises from $300 \mathrm{~K}$ to $370 \mathrm{~K}$, the threshold voltage shifts about $0.95 \mathrm{~V}$ with SNT. Compared with that without SNT, the threshold voltage shifts decrease by $0.45 \mathrm{~V}$.
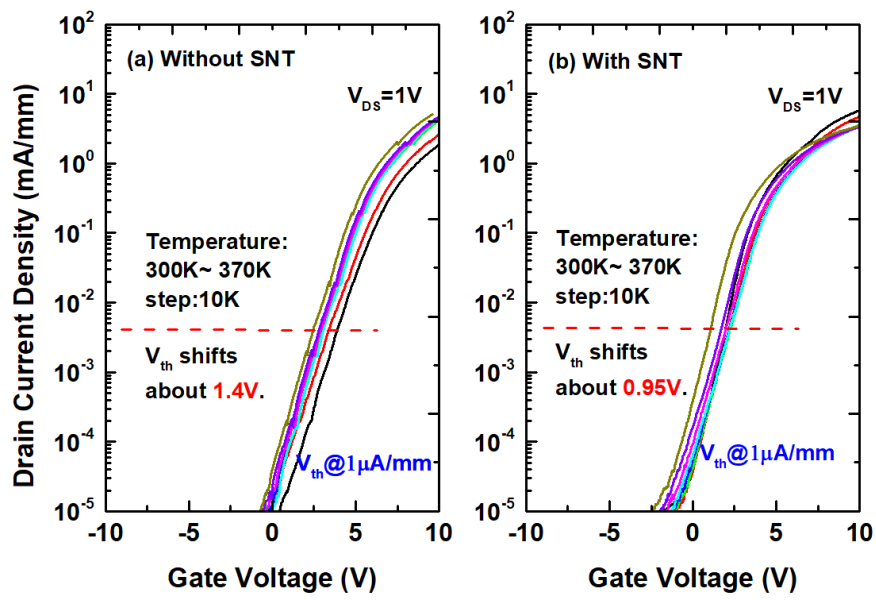

Figure 5. Temperature-dependent transfer characteristics of the all-GaN integrated MIS-HEMTs (a) without SNT and (b) with SNT.

To further study the effect of SNT on the shift of $\mathrm{V}_{t h}$ after various time intervals and different gate-bias-induced stresses, time-of-fly gate-bias-induced stress and $\mathrm{V}_{\text {th }}$ measurement have been performed on the device with both positive and negative gate biases. The shift of $\mathrm{V}_{t h}$ with bias-induced stress time from $1 \mathrm{~ms}$ to $1000 \mathrm{~s}$ at different voltages is shown in Figure 6.The shift of $\mathrm{V}_{t h}$ shows a nearly linear relationship with logarithmic time scale, suggesting broad distribution of the time constant of deep traps in the devices without SNT. On the other hand, the shift of $\mathrm{V}_{t h}$ in the all-GaN MIS-HEMTs with SNT after the stress is much smaller. The maximum shift of $\mathrm{V}_{t h}$ at $8 \mathrm{~V}$ gate stress for $1000 \mathrm{~s}$ is only $0.58 \mathrm{~V}$.
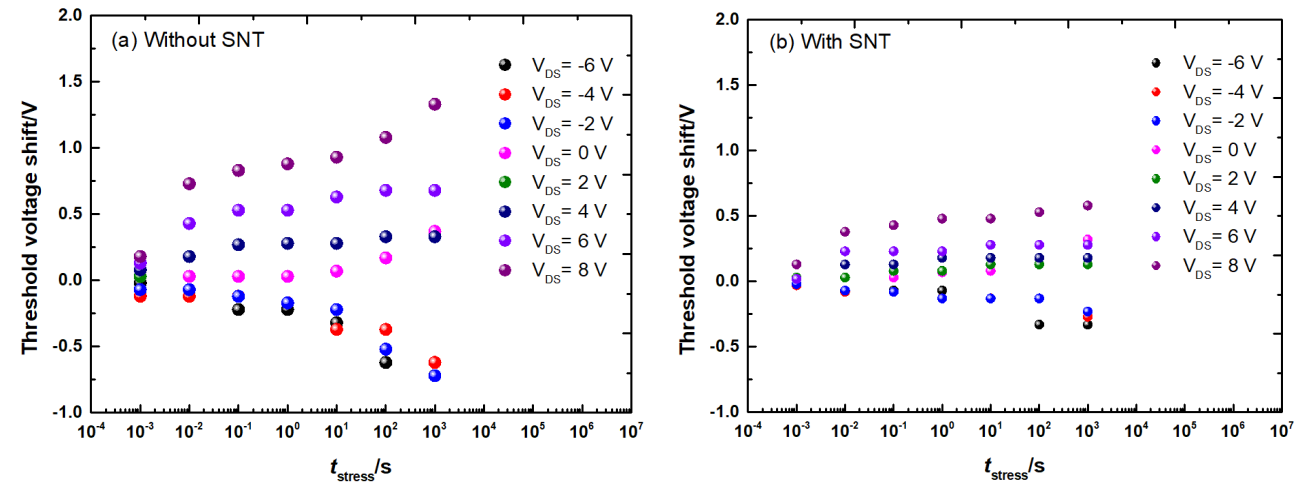

Figure 6. Stress-sequence of the all-GaN integrated MIS-HEMTs (a) without SNT and (b) with SNT.

\section{3. $\mathrm{Si}_{3} \mathrm{~N}_{4} / \mathrm{AlGaN}$ Interface Trap Characterization}

Figure 7 shows the Ga $3 \mathrm{~d}$ (left), $\mathrm{Al} 2 \mathrm{p}$ (middle) and $\mathrm{Si} 2 \mathrm{p}$ (right) core-level spectra at the $\mathrm{Si}_{3} \mathrm{~N}_{4} / \mathrm{AlGaN}$ interface in the 8-nm $\mathrm{Si}_{3} \mathrm{~N}_{4} / \mathrm{AlGaN} / \mathrm{GaN}$ samples, which is simulated by Avantage. For the control sample without SNT, the native oxide exhibits a large shoulder (Ga-O bonds) on the high binding energy side of the Ga-N peak [Figure 7a left]. The Ga $3 \mathrm{~d}$ core-level spectrum in Figure 7a indicates the existence of amorphous native 
oxide at the $\mathrm{Si}_{3} \mathrm{~N}_{4} / \mathrm{AlGaN}$ interface without SNT. Ga-O/Al-O/Si-O bonds may also be a kind of the interface state [19], which could lead to the $\mathrm{V}_{\text {th }}$ shift phenomena in GaN MIS-HEMTs. During the formation of $\mathrm{Ga}-\mathrm{O} / \mathrm{Al}-\mathrm{O} / \mathrm{Si}-\mathrm{O}$ bonds, some of them are natural oxidation and some are $\mathrm{O}$ filled with $\mathrm{N}$ vacancy. With SNT, a higher intensity of Al-N bonds is observed at the $\mathrm{Si}_{3} \mathrm{~N}_{4} / \mathrm{AlGaN}$ interface [Figure $7 \mathrm{~b}$ middle]. The proportion of Ga-N bonds increases from 79.01-89.35\%. The proportion of Al-N bonds increases from $69.72-85.01 \%$. The proportion of Si-N bonds increases from $65.63-83.61 \%$. At the same time, the proportion of Ga dangling bonds decreases from $0.08-0.06 \%$. The proportion of $\mathrm{Al}$ dangling bonds decreases from $1.16-0.37 \%$. The proportion of $\mathrm{Si}$ dangling bonds decreases from $1.25-0.54 \%$. The change of the proportion of chemical bonds indicates that part of the $\mathrm{N}$ vacancies is filled, and some $\mathrm{O}$ atoms in $\mathrm{Ga}-\mathrm{O}$ bonds are replaced by $\mathrm{N}$ during SNT treatment.

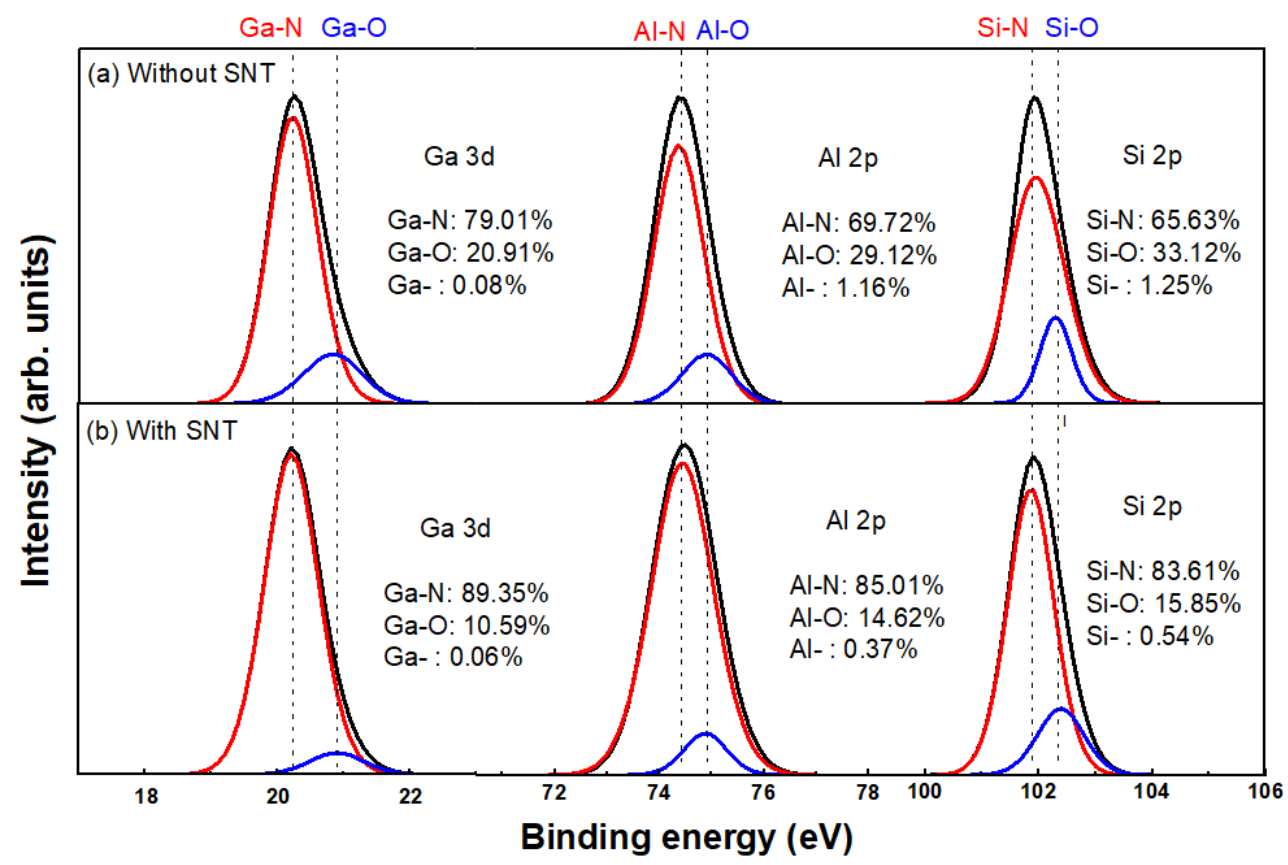

Figure 7. Ga $3 \mathrm{~d}$ (left), $\mathrm{Al} 2 \mathrm{p}$ (middle) and $\mathrm{Si} 2 \mathrm{p}$ (right) core-level spectra at the $\mathrm{Si}_{3} \mathrm{~N}_{4} / \mathrm{AlGaN}$ interface in the 8-nm $\mathrm{Si}_{3} \mathrm{~N}_{4} / \mathrm{AlGaN} / \mathrm{GaN}$ samples (a) without SNT and (b) with SNT. Each measured spectrum (symbol) is resolved into two Gaussian functions that correspond to $\mathrm{M}$ in $\mathrm{M}-\mathrm{N}$ (solid red line) and M-O (solid blue line) bonds. M represents Ga (left), $\mathrm{Al}$ (middle) or Si (right). The solid blue red line is a superposition of the two fitting functions.

$\mathrm{CO}_{2}$ is a double bond structure with large structure with large activation energy and stable chemical properties. It does not participate in the reaction during supercritical nitridation treatment. It acts only as a solvent for supercritical $\mathrm{NH}_{3}$, avoiding the supercritical $\mathrm{NH}_{3}$ reaction and eroding the device electrodes. As mentioned above, due to the dry etch process and high growth temperature in LPCVD, the very surface of the AlGaN layer and the interface between $\mathrm{Si}_{3} \mathrm{~N}_{4}$ and AlGaN layer may be relatively defective, which could lead to the trap-induced $\mathrm{V}_{\text {th }}$ shift phenomena in GaN MIS-HEMTs [20].

Figure 8 shows the supercritical nitridation technology model of the fabricated allGaN integrated MIS-HEMTs, which is simulated by Nanodcal.In the process of SNT, $\mathrm{NH}_{2}^{-}$ produced by auto coupling ionization of $\mathrm{NH}_{3}$ has strong nucleophilic ability and can fill the nitrogen vacancy near the $\mathrm{Si}_{3} \mathrm{~N}_{4} / \mathrm{AlGaN}$ interface caused by the dry etch and high temperature process. During the nucleophilic reaction [21], $\mathrm{NH}_{2}^{-}$can react with $\mathrm{Ga}-\mathrm{O} / \mathrm{Al}-\mathrm{O} / \mathrm{Si}-\mathrm{O}$ to replace $\mathrm{O}$ and from the Ga-N/Al-N/Si-N bonds. The exact passivation mechanism during SNT is still under investigation. 


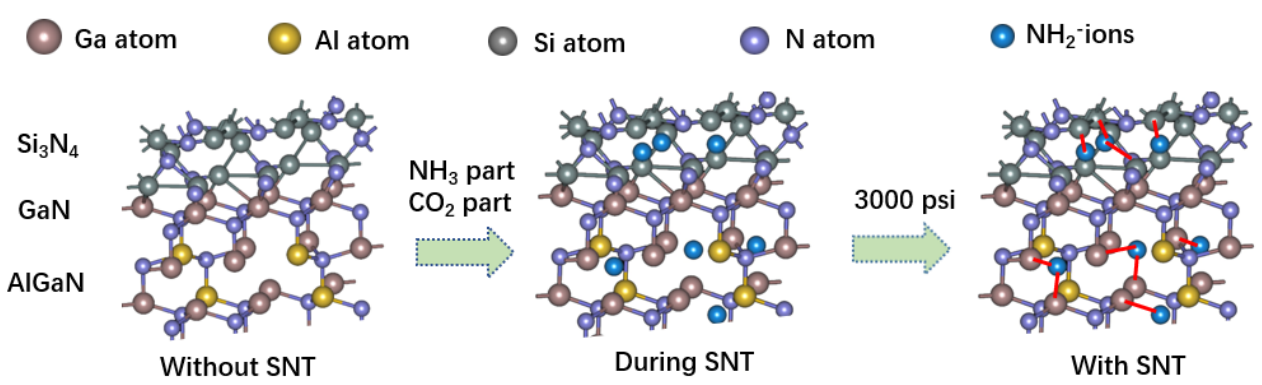

Figure 8. The supercritical nitridation technology model of the fabricated all-GaN integrated MISHEMTs.

\section{Conclusions}

In summary, high performance AlGaN/GaN MIS-HEMTs realized via supercritical nitridation technology has been designed, fabricated, and measured. By comparing the devices without and with SNT, we find that supercritical nitridation technology can effectively repair the defects and suppress the shift of threshold voltage. With SNT, the optimized MIS-HEMTs demonstrate a low $\mathrm{V}_{\text {th }}$ shift decrease of about $0.54 \mathrm{~V}$ at $\mathrm{V}_{G_{s} \text { weep }}$ from $0 \mathrm{~V}$ to $15 \mathrm{~V}$. Our demostration of the supercritical nitridation technology to repair defects of wide-bandgap family of semiconductors may bring about great changes in the field of device fabrication.

Author Contributions: Conceptualization, M.L.; methodology, M.L.; software, M.L.; validation, M.L. and Y.J.; investigation, M.L.; resources, M.L.; data curation, M.L.and Y.Y.; writing-original draft preparation, M.L.; writing-review and editing, M.L. and L.L.; visualization, M.L.; supervision, Y.J. and C.C.; project administration, Y.J.; funding acquisition, Y.J. All authors have read and agreed to the published version of the manuscript.

Funding: This research was funded by the Shenzhen Science and Technology Innovation Committee (grant number: ZDSYS201802061805105 and JCYJ20190808155007550). Among them grant ZDSYS201802061805105 is the TSV 3D Integrated Micro/Nanosystem Laboratory program.

Institutional Review Board Statement: Not applicable.

Informed Consent Statement: Not applicable.

Data Availability Statement: All data, models, and code generated or used during the study appear in the submitted article.

Conflicts of Interest: The authors declare no conflict of interest.

\section{References}

1. Wu, T.L.; Tang, S.W.; Jiang, H.J. Investigation of Recessed Gate AlGaN/GaN MIS-HEMTs with Double AlGaN Barrier Designs toward an Enhancement-Mode Characteristic. Micromachines 2020, 11, 163. [CrossRef] [PubMed]

2. Chen, K.J.; Häberlen, O.; Lidow, A.; Tsai, C.L.; Ueda, T.; Uemoto, Y.; Wu, Y. GaN-on-Si Power Technology: Devices and Applications. IEEE Trans. Electron Devices 2017, 64, 779-795. [CrossRef]

3. Jiang, S.; Lee, K.B.; Guiney, I.; Miaja, P.F.; Zaidi, Z.H.; Qian, H.T.; Wallis, D.J.; Forsyth, A.J.; Humphreys, C.J.; Houston, P.A. All-GaN-Integrated Cascode Heterojunction Field Effect Transistors. IEEE Trans. Power Electron. 2017, 32, 8743-8750. [CrossRef]

4. Liu, Z.Y.; Huang, X.C.; Lee, F.C.; Li,Q. Package Parasitic Inductance Extraction and Simulation Model Development for the High-Voltage Cascode GaN HEMT. IEEE Trans. Power Electron. 2014, 29, 1977-1985. [CrossRef]

5. Du, W.J.; Huang, X.C.; Lee, F.C.; Li, Q.; Zhang, W.L. Avoiding divergent oscillation of cascode GaN device under high current turn-off condition. In Proceedings of the 2016 IEEE Applied Power Electronics Conference and Exposition (APEC), Long Beach, CA, USA, 20-24 March 2016; pp. 1002-1009.

6. Sun, W.W.; Zheng, X.F.; Fan, S.; Wang, C.; Du, M.; Zhang, K.; Chen, W.W.; Cao, Y.R.; Mao, W.; Ma, X.H.; et al. Degradation mechanism of enhancement-mode $\mathrm{AlGaN} / \mathrm{GaN}$ HEMTs using fluorine ion implantation under the on-state gate overdrive stress. Chin. Phys. B 2015, 24, 017303. [CrossRef]

7. Saito, W.; Nitta, T.; Kakiuchi, Y.; Saito, Y.; Tsuda, K.; Omura, I.; Yamaguchi, M. Suppression of Dynamic On-Resistance Increase and Gate Charge Measurements in High-Voltage GaN-HEMTs With Optimized Field-Plate Structure. IEEE Trans. Electron Devices 2007, 54, 1825-1830. [CrossRef] 
8. Uesugi, T.; Kachi, T. Which are the Future GaN Power Devices for Automotive Applications, Lateral Structures or Vertical Structures. In Proceedings of the CS MANTECH Conference, Palm Springs, CA, USA, 16-19 May 2011; pp. 307-310.

9. Wu, T.L.; Marcon, D.; De Jaeger, B.; Van Hove, M.; Bakeroot, B.; Stoffels, S.; Groeseneken, G.; Decoutere, S.; Roelofs, R. Time Dependent Dielectric Breakdown (TDDB) evaluation of PE-ALD SiN gate dielectrics on AlGaN/GaN recessed gate D-mode MIS-HEMTs and E-mode MIS-FETs. In Proceedings of the 2015 IEEE International Reliability Physics Symposium, Monterey, CA, USA, 19-23 April 2015; pp. 6C.4.1-6C.4.6.

10. Uemoto, Y.; Hikita, M.; Ueno, H.; Matsuo, H.; Ishida, H.; Yanagihara, M.; Ueda, T.; Tanaka, T.; Ueda, D. Gate Injection Transistor (GIT)-A Normally-Off AlGaN/GaN Power Transistor Using Conductivity Modulation. IEEE Trans. Electron Devices 2007, 54, 3393-3399. [CrossRef]

11. Dutta, G.; Dasgupta, N.; Dasgupta, A. Effect of Sputtered- $\mathrm{Al}_{2} \mathrm{O}_{3}$ Layer Thickness on the Threshold Voltage of III-Nitride MIS-HEMTs. IEEE Trans. Electron Devices 2016, 63, 1450-1458. [CrossRef]

12. Zhang, Z.L.; Li, W.Y.; Fu, K.; Yu, G.H.; Zhang, X.Z.; Zhao, X.D.; Zhao, Y.F.; Sun, S.C.; Song, L.; Deng, X.G.; et al. AlGaN/GaN MIS-HEMTs of Very-Low Vth Hysteresis and Current Collapse with In-Situ Pre-Deposition Plasma Nitridation and LPCVD-Si ${ }_{3} \mathrm{~N}_{4}$ Gate Insulator. IEEE Electron Device Lett. 2017, 38, 236-239. [CrossRef]

13. Wu, C.H.; Han, P.C.; Liu, S.C.; Hsieh, T.E.; Lumbantoruan, F.J.; Ho, Y.H.; Chen, J.Y.; Yang, K.S.; Wang, H.C.; Lin, Y.K.; et al. High-Performance Normally-OFF GaN MIS-HEMTs Using Hybrid Ferroelectric Charge Trap Gate Stack (FEG-HEMT) for Power Device Applications. IEEE Electron Device Lett. 2018, 39, 991-994. [CrossRef]

14. Ikeda, N.; Niiyama, Y.; Kambayashi, H.; Sato, Y.; Nomura, T.; Kato, S.; Yoshida, S. GaN Power Transistors on Si Substrates for Switching Applications. Proc. IEEE. 2010, 98, 1151-1161. [CrossRef]

15. Benoit, D.; Regolini, J.; Morin, P. Hydrogen desorption and diffusion in PECVD silicon nitride. Application to passivation of CMOS active pixel sensors. Microelectron. Eng. 2007, 84, 2169-2172. [CrossRef]

16. Tsai, C.T.; Chang, K.M.; Liu, P.T.; Kuo, Y.L.; Kin, K.T.; Chang, P.L.; Huang, F.S. Low-temperature method for enhancing sputter-deposited $\mathrm{HfO}_{2}$ films with complete oxidization. Appl. Phys. Lett. 2007, 91, 012109. [CrossRef]

17. Chang, K.C.; Pan, C.H.; Chang, T.C.; Tsai, T.M.; Zhang, R.; Lou, J.C.; Young, T.F.; Chen, J.H.; Shih, C.C.; Chu, T.J.; et al. Hopping effect of hydrogen-doped silicon oxide insert RRAM by supercritical $\mathrm{CO}_{2}$ fluid treatment. IEEE Electron Device Lett. 2013, 34, 617-619. [CrossRef]

18. Chattopadhyay, P.; Gupta, R.B. Production of griseofulvin nanoparticles using supercritical $\mathrm{CO}_{2}$ antisolvent with enhanced mass transfer. Int. J. Pharm. 2001, 228, 19-31. [CrossRef]

19. Robertson, J. Model of interface states at III-V oxide interfaces. Appl. Phys. Lett. 2009, 94, 214-215. [CrossRef]

20. Hashizume, T.; Hasegawa, H. Effects of nitrogen deficiency on electronic properties of AlGaN surfaces subjected to thermal and plasma processes. Appl. Surf. Sci. 2004, 234, 387-394. [CrossRef]

21. Yu, J.S.; Liu, Y.L.; Tang, J.; Wang, X.; Zhou, J. Highly efficient "on water" catalyst-free nucleophilic addition reactions using difluoroenoxysilanes: Dramatic fluorine effects. Angew. Chem. 2014, 53, 9512-9516. [CrossRef] [PubMed] 